\title{
Use of Remote Sensing for Monitoring Climate Variability for Integrated Early Warning Systems: Applications for Human Diseases and Desert Locust Management
}

\author{
Pietro Ceccato, Michael A. Bell, M. Benno Blumenthal, Stephen J. Connor, Tufa Dinku, Emily K. Grover-Kopec, \\ Chester F. Ropelewski, Madeleine C. Thomson \\ International Research Institute for Climate and Society (IRI), \\ The Earth Institute, Columbia University, \\ Palisades, NY, USA. \\ Email: pceccato@iri.columbia.edu
}

\begin{abstract}
A number of the major human infectious diseases (like malaria and dengue) and Desert Locusts that still plague the developing world are sensitive to inter-seasonal and inter-decadal changes in environment and climate. Monitoring variations in environmental conditions such as rainfall and vegetation helps decision-makers at Ministries of Agriculture and Ministries of Health to assess the risk levels of Desert Locust outbreaks or malaria epidemics. The International Research Institute for Climate and Society (IRI) has developed products based on remotely sensed data to monitor those changes and provide the information directly to the decision-makers. This paper presents recent developments which use remote sensing to monitor climate variability, environmental conditions and their impacts on the dynamics of infectious diseases (malaria) and Desert Locust outbreaks.
\end{abstract}

Keywords: Human Health, Desert Locust, Early Warning Systems, Rainfall Estimates, TERRA-MODIS images, GIS.

\section{INTRODUCTION}

A number of the major human infectious diseases (like malaria and dengue) and Desert Locust that still plague the developing world are sensitive to inter-seasonal and interdecadal changes in environment and climate [1,2]. Monitoring variations in environmental conditions such as rainfall and vegetation helps decision-makers at Ministries of Agriculture and Ministries of Health to assess the risk levels of Desert Locust outbreaks or malaria epidemics. The International Research Institute for Climate and Society (IRI) has developed products based on remotely sensed data to monitor those changes and provide the information directly to the decisionmakers. The mission of the IRI is to enhance society's capability to understand, anticipate and manage the impacts of seasonal climate fluctuations, in order to improve human welfare and the environment, especially in developing countries.

This paper presents recent developments which use remote sensing to monitor climate variability, environmental conditions and their impacts on the dynamics of infectious diseases (malaria) and Desert Locust outbreaks.

\section{The Role of Climate}

\section{A. Climate and Malaria}

Given its impact on populations and the gravity of its pathology, malaria remains one of the most significant infectious diseases. It is essentially an environmental disease since the vectors require specific habitats with surface water for reproduction, humidity for adult mosquito survival and the development rates of both the vector and parasite populations are influenced by temperature. In Sub-Saharan Africa the pattern of malaria transmission varies markedly from region to region, depending on climate and biogeography.

The association between rainfall and malaria epidemics has been recognized for many decades [3], but while increasing precipitation may increase vector populations in many circumstances by increasing available anopheles breeding sites, excessive rains may also have the opposite effect by flushing out small breeding sites, such as ditches or pools [4], or by decreasing the temperature, which in regions of higher altitude can hinder malaria transmission. 
Temperature also plays an important role in the variability of malaria transmission. The development rate of mosquito larvae and the malaria parasite within the mosquito host is highly regulated by temperature. It is also one of the factors that influence the survival rate of mosquitoes. Generally, mosquitoes develop faster and feed earlier in their life cycle and at a higher frequency in warmer conditions. The plasmodium parasite also multiplies more rapidly in the mosquito in higher temperatures $[5,6]$. Humidity impacts the survival rate of the mosquito as well. Mosquitoes will generally not live long enough to complete their transmission cycle where relative humidity is constantly less than $60 \%[5,6$, 7].

\section{B. Climate and Desert Locust}

During the summer of 2003, several African countries were swept by swarms of Desert Locust in what was the worst locust crisis in the region since 1986-89. The situation was particularly critical in Algeria, Mali, Mauritania, Morocco, Niger and Senegal. Successive above-average rainfall accumulations, first in the Sahel and then in Northwest Africa from July 2003 to April 2004 [8], led to ideal breeding conditions for the Desert Locust, thus changing a rare, solitary, harmless insect into the swarms so feared by farmers. The Desert Locust (Schistocerca gregaria, Forskål 1775) lives in remote desert zones extending from North Africa to Southwest Asia which are far from populated centers and therefore difficult to access. During quiet periods (known as recessions) Desert Locusts are usually restricted to the semi-arid and arid deserts of Africa, the Near East and South-West Asia.

When conditions are favorable for reproduction (i.e. moist sandy/clay soils for egg-laying and green vegetation for hopper development) Desert Locusts increase in number and change their behavior from that of acting as an individual (solitarious) insect to that as acting as part of a group (gregarious). The appearance of the locust also changes: solitary adults are brown whereas gregarious adults are pink (immature) and yellow (mature). During invasion periods, gregarious adults form swarms that can fly with the wind over great distances and threaten crops and pastures in about 50 countries. Locust swarms can vary from less than one square kilometer to several hundred square kilometers. There can be at least 40 million and sometimes as many as 80 million locust adults in each square kilometer of swarm. A Desert Locust adult can consume roughly its own weight in fresh food per day, that is about two grams every day. A very small part of an average swarm (or about one tone of locusts) eats the same amount of food in one day as about 10 elephants or 25 camels or 2,500 people [15]. The Desert Locust plague of 1986-89 and subsequent upsurges in 1992-94 and 1996-98 demonstrated how quickly this pest increases in number and spreads across national borders adversely affecting economies and the environment in locust-prone countries.

In order to avoid extensive and costly operations, it is necessary to detect Desert Locust populations at the outbreak or early upsurge stages before their populations can expand into full-scale plagues. To achieve detection of Desert Locust at an early stage, survey teams must visit potential breeding areas to assess the condition of the habitat and the state of any Desert Locust populations. The potential breeding areas cover areas that are spread over vast regions that are remote and difficult to access. To survey them involves considerable preparation and travel time, costly transport, as well as significant financial and staff resources. Reaching them all on a regular basis presents serious logistical problems. Availability of transportation and operational allotments are limiting factors. Survey teams cannot afford to monitor the potential areas by guesswork, without knowing exactly where to find vegetation conditions that are favorable to Desert Locust reproduction. The use of satellite images combined with a Geographical Information System provide an early warning system which can be used to direct field survey teams towards regions with a high potential for Desert Locust infestation and to estimate control measures required.

\section{The Use of Remote Sensing}

\section{A. Monitoring Rainfall}

In the majority of the countries in Africa, monitoring rainfall is a major problem due to the insufficient coverage of rain gauges. Therefore, it is necessary to use rainfall estimations derived from satellite measurements. Using rainfall estimate products updated approximately every 10 days through the Africa Data Dissemination Service (ADDS), which is maintained by the United States Geological Survey (USGS) and supported by the U. S. Agency for International Development (USAID), staff working at the International Research Institute for Climate and Society (IRI) have developed a web-based Malaria Early Warning System (MEWS) interface which enables the user to gain a contextual perspective of the current rainfall season by comparing it to previous seasons and recent short-term averages.

The interface is in the IRI Data Library and takes the form of an online 'clickable map': http://iridl.ldeo.columbia.edu/maproom/.Health/.Regional/.Afri ca/.Malaria/.MEWS/. It displays the most recent dekadal rainfall map (Fig. 1) over which national and district administrative boundaries and the epidemic risk zone can be overlaid (in this case as a guide rather than an absolute mask which excludes districts which may be of local interest). 
Clickable Map for Rainfall Summaries

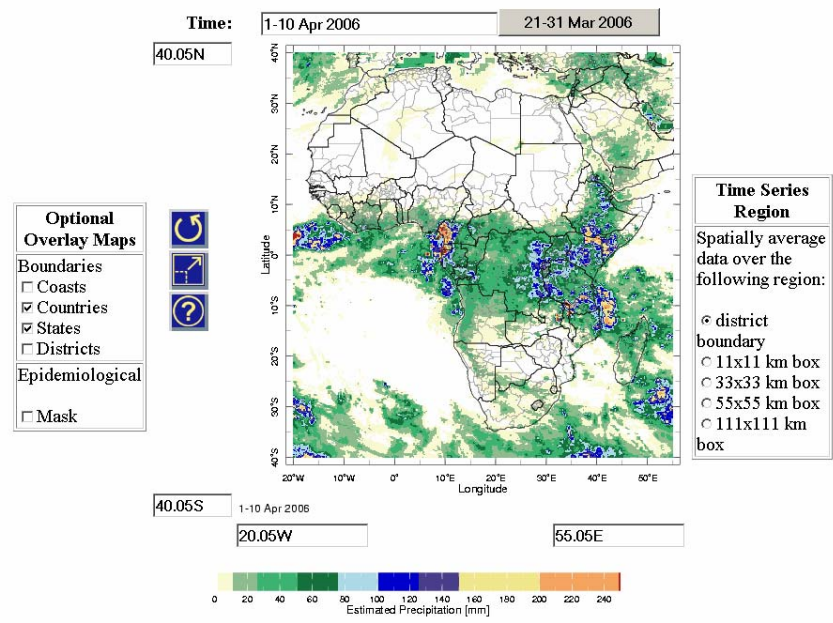

\begin{tabular}{|c|c|c|c|}
\hline \multicolumn{4}{|c|}{ Dataset Documentation } \\
\hline \multicolumn{4}{|c|}{$\begin{array}{l}\text { Precipitation Estimates } \\
\text { Data: Dekadal precipitation estimates on a } 0.1 \text { x } 0.1 \text { deg. lat/lon grid } \\
\text { Data Source: Climate Prediction Center/Famine Early Warning System (CPC/FEWS } \\
\text { RFE2.0 })^{*}\end{array}$} \\
\hline \multicolumn{4}{|c|}{$\begin{array}{l}\text { Epidemiological Mask } \\
\text { Data: Mask illustrating areas where malaria is considered to be epidemic. Areas where } \\
\text { malaria transmission is considered absent or endemic are therefore excluded. This mask is } \\
\text { based purely on climatic constraints to malaria transmission, and does not yet account for } \\
\text { areas in the northern and southern margins of the continent where control has eliminated } \\
\text { malaria risk. } \\
\text { Reference: WHO: Final report on the 3rd meeting of the RBM Technical Resource Network } \\
\text { on Epidemic Prevention and Control. Geneva: World Health Organization; } 2002 \text {. } \\
\text { *More dekadal and daily data from FEWS is available from the Africa Data Dissemination } \\
\text { Service. }\end{array}$} \\
\hline & load Map & Download Layer & Download Data \\
\hline$\frac{\text { Figure as }}{\underline{\text { PDF }}}$ & $\underline{\text { Figure as JPEG }}$ & & \\
\hline$\frac{\text { Colorscale as }}{\underline{\text { PDF }}}$ & Colorscale as JPEG & ID & Da \\
\hline
\end{tabular}

Figure 1. MEWS ‘Clickable Map’ for Rainfall Monitoring 1-10 Apr 2006

These visual features can be toggled on or off and the user can zoom in to any region for more clarity. In addition, the map can be downloaded in different formats compatible with common Image Analysis and Geographical Information Systems (GIS) software such as ArcView ${ }^{\circledR}$ or HealthMapper (free GIS software developed by UN World Health Organization).

Dekadal rainfall can be spatially averaged over a variety of user-selected areas, including administrative districts and $11 \times 11 \mathrm{~km}, 33 \times 33 \mathrm{~km}, 55 \times 55 \mathrm{~km}$ and $111 \times 111 \mathrm{~km}$ boxes. Upon the selection of this sampling area and a specific location of interest (by a click on map at location of interest), four timeseries graphs are generated (Fig. 2). These time-series provide an analysis of recent rainfall with respect to that of recent seasons and the long-term series. A description of the timeseries figures, the data used and its source is also provided [9].
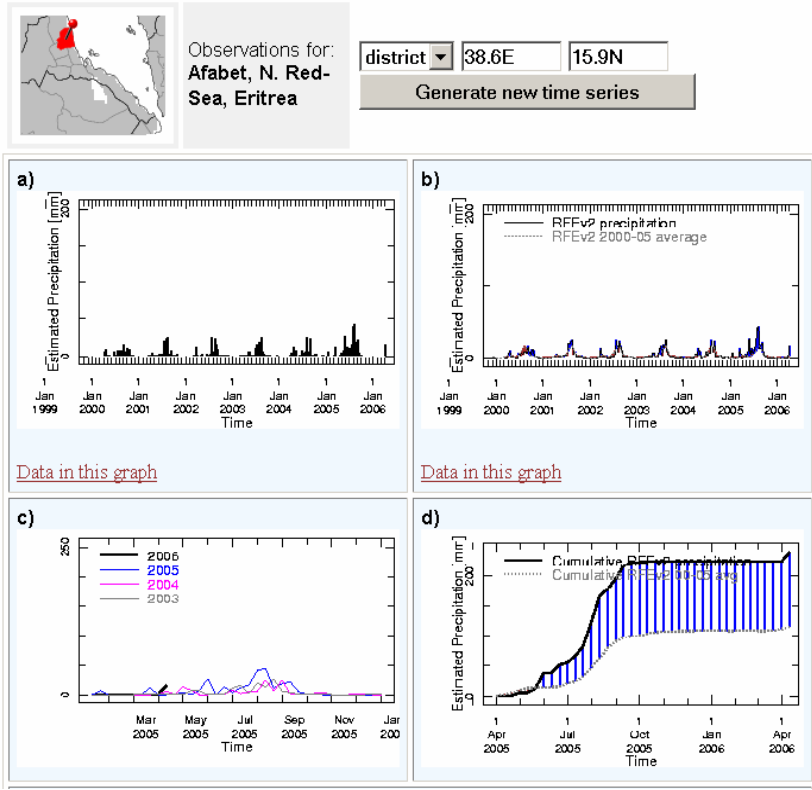

Description

a) Dekadal (i.e., 10-daily) precipitation estimates for the selected region from Dec 1999 to the present

b) Same as (a) (solid black line) with the addition of the recent short-term average precipitation for the same region (grey dotted line). The blue (red) bars are indicative of estimates that are above (below) the short-term average. Note that the short-term average precipitation data has been smoothed.

c) Same as (a) for the current year (thick black line), as indicated by the axis labels. Precipitation estimates from previous years are also shown (blue-1 yr from present magenta- 2 yrs from present; grey-3 yrs from present.

d) Cumulative dekadal satellite-derived precipitation estimates (solid black line) and the cumulative recent short-term average precipitation (grey dotted line) for the most recent

12 -month period in the selected region. The blue (red) bars are indicative of estimates that are above (below) the short-term average.

NOTE: The recent short-term (e.g. 6-year) average of precipitation should not be interpreted as a climatological normal, which is typically based on a long-term (e.g., 30year) time series. The length of this short-term average will increase over time as more data becomes available. (An additional year of data will included in the average during January of each year ) Despite the limitations that the short-term average imposes, it may January of each year.) Despite the limitations that the short-term average imposes, it may principal cause of malaria epidemics by providing a recent historical reference.

\section{Data Sources}

Rainfall Estimates

Data: Dekadal precipitation on a $0.1 \times 0.1 \mathrm{deg}$. lat/lon grid

Data Source: Climate Prediction Center/Famine Early Warning System ( $\mathrm{CPC} / \mathrm{FEWS}$ $\underline{\mathrm{RFE} 2.0)^{*}}$

Rainfall Estimate Short-Term Average

Data: Dekadal precipitation on a $0.1 \times 0.1 \mathrm{deg}$. lat/lon grid

Base Period: 1 Jan 2000 to 31 Dec 2005

Data Source: Climate Prediction Center/Famine Early Warning System (CPC/FEWS $\underline{\mathrm{RFE} 2.0)^{*}}$

*More dekadal and daily data from FEWS is available from the Africa Data Dissemination Service.

Figure 2. Four time-series graphs are generated and provide an analysis of recent rainfall with respect to that of recent seasons and the long-term series.MEWS ‘Clickable Map’ for Rainfall Monitoring 1-10 Apr 2006

The above Rainfall Estimate product will be replaced in the near future with a relatively new product from NOAACPC named the CPC morphing technique (CMORPH) [14] which has exhibited better agreement with field measurements [10]. 


\section{B. Monitoring Vegetation and Water Bodies}

Vegetation type and growth stage play an important role in determining mosquito and Desert Locust abundance irrespective of their association with rainfall. The type of vegetation which surrounds the breeding sites, and thereby provides, food, potential resting and protection from climatic conditions are also important in determining the abundance of mosquitoes and Desert Locusts [2,11]. Surface water provides the habitat for the juvenile stages (egg, larvae, pupae) of malaria vectors. Monitoring the state of water bodies and wetlands is therefore important to identify the source of malaria vectors.

In order to monitor vegetation and water bodies, TERRA-MODIS images (at $250 \mathrm{~m}$ spatial resolution) were selected. MODIS images were chosen because they provide frequent images at high spatial resolution and are available free of charge (an important requirement considering the economic realities of the countries in the affected region).

The products (vegetation indices 16-day L3 Global 250M SIN GRID V004) are automatically downloaded from the USGS Land Processes Distributed Active Archive Center (LanDAAC) and provided to the user community via the IRI Data Library web site: http://iridl.ldeo.columbia.edu/SOURCES/.USGS/.LandDAAC/. MODIS/.

The users can download either the raw data which are the single channels in the blue, red, near-infrared (NIR) and short-wave infrared (SWIR) wavelengths in different formats compatible with common Image Analysis and Geographical Information Systems (GIS) software as well as the Normalized Difference Vegetation Index (NDVI) and Enhanced Vegetation Index (EVI) [12]. Using the IRI Data Library, the users can remotely (via Internet):

- Combine the different channels to create their own tailored vegetation indices for monitoring (e.g. vegetation status in terms of moisture content by using a combination of the NIR-SWIR [13])

- $\quad$ Visualize a color composite of the SWIR-NIR and Red channels (Red-Green-Blue) where the vegetation appears in green, the bare soils in brown and the water in blue [2]

- Integrate the color composite into GIS software with ancillary data such as roads and villages (Fig. 3)

- $\quad$ Extract weighted averages of the different indices per GIS layers such as district contours or any other shape file

- $\quad$ Create long-term series of vegetation indices

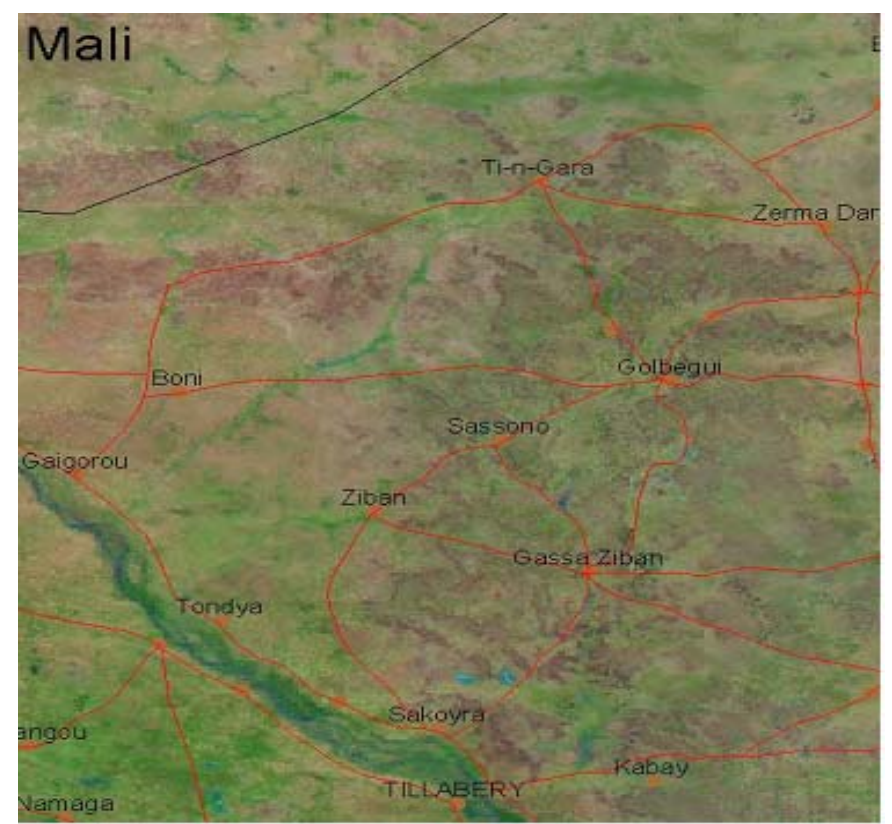

Figure 3. TERRA-MODIS color composite RGB where the SWIR channel is in Red, the NIR channel in Green and the RED channel in Blue. The satellite image covers an area of roughly $200 \mathrm{~km}^{2}$ in the North of Niamey, Niger during the rainy season. The water bodies (in blue) are breeding sites for mosquitoes and locations where the nomads gather to water their cattle.

The TERRA-MODIS images currently available through the IRI Data Library cover West Africa, Horn of Africa, Madagascar and South America but other regions in Africa and Asia will soon be added to the IRI Data Library.

\section{SUMMARY}

The rainfall, vegetation and water body monitoring products presented here above are operationally used by Ministries of Health for malaria control and Ministries of Agriculture for Desert Locust monitoring. They allow the users to forecast the risk of malaria epidemics or Desert Locust outbreaks. In addition to the two operational examples provided for human health and pest management, the products can also potentially be used for other objectives such as natural disasters related to drought, floods and food security management purposes.

\section{ACKNOWLEDGMENT}

We would like to thank Joaquim DaSilva (UN World Health Organization), Samson Katikiti (WHO), Jacques André Ndione (Centre de Suivi Ecologique de Dakar, Senegal), JeanDésiré Rakotoson, and Harilala Ranaivoharimina (Ministère de la Santé, Institut d'Hygiène Sociale, Antananarivo, Madagascar), Tewolde Ghebremeskel and Selam Mihreteab (National Malaria Control Program, Ministry of Health, Asmara, Eritrea), for their input and technical assistance. 


\section{REFERENCES}

[1] M.C. Thomson, F. J. Doblas-Reyes, S. J. Mason, R. Hagedorn, S. J. Connor, T. Phindela, A. P. Morse, T. N. Palmer. "Malaria early warnings based on seasonal climate forecasts from multi-model ensembles". Nature, 439, 576-579, 2006.

[2] P. Ceccato. "Operational Early Warning System Using SPOT-VGT and TERRA-MODIS to Predict Desert Locust Outbreaks". In Proceedings of the 2nd VEGETATION International Users Conference, 24-26 March 2004, Antwerpen. Editors: Veroustraete, F., Bartholomé, E., Verstraeten, W.W. Luxembourg: Luxembourg: Office for Official Publication of the European Communities, ISBN 92-894-9004-7, EUR 21552 EN, 475 p, 2005.

[3] S.R. Christophers. "Malaria in the Punjab". Scientific memoirs, by officers of the medical and sanitary departments of India. New Series: 46-197, 1911.

[4] R.M. Fox. "Anopheles gambiae in relation to malaria and filariasis in coastal Liberia". American Journal of Tropical Medicine and Hygiene, 6: 598-620, 1957.

[5] H.M. Gilles, D.A. Warrell (eds): "Bruce-Chwatt's Essential Malariology". Arnold Publishing: 340pp 1993.

[6] Committee on Climate, Ecosystems, Infectious Disease, and Human Health: Under the Weather: Climate, Ecosystems and Infectious Disease. Washington, D.C.: National Research Council; 146pp, 2001.

[7] E. Pampana. "A textbook of malaria eradication". London: Oxford University Press; 1969.

[8] M. Bell. "The 2004 desert locust outbreak". Bulletin of the American Meteorology Society, 86 (6): S60-S60 Jun 2005.
[9] E.K. Grover-Kopec, M. Kawano, R.W. Klaver, B. Blumenthal, P. Ceccato, and S.J. Connor. "An online operational rainfall-monitoring resource for epidemic malaria early warning systems in Africa”. Malaria Journal, 4, 1-6, 2005.

[10] T. Dinku, P. Ceccato, E. Grover-Kopec, M. Lemma, S.J. Connor, C.F. Ropelewski. "Validation and inter-comparison of satellite rainfall products over East African complex topography" International Journal of Remote Sensing. Submitted.

[11] L.R. Beck, M.H. Rodriguez, S.W. Dister, A.D. Rodriguez, E. Rejmankva, A. Ulloa, R.A. Meza, D.R. Roberts, J.F. Paris, M.A. Spanner, R.K. Washino, C. Hacker, L.J. Legters. "Remote sensing as a landscape epidemiological tool to identify villages at high risk for malaria transmission" American Journal of Tropical Medecine and Hygiene, 51(3): 271-280, 1994.

[12] A. Huete, K. Didan, T. Miura, E.P. Rodriguez, X. Gao, L.G. Ferreira. "Overview of the radiometric and biophysical performance of the MODIS vegetation indices.”. Remote Sensing of Environment, 83: 195$213,2002$.

[13] P. Ceccato, N. Gobron, S. Flasse, B. Pinty, S. Tarantola. "Designing a spectral index to estimate vegetation water content from remote sensing data (Part 1: theoretical approach)". Remote Sensing of Environment, 82 (2-3): 188-197, 2002.

[14] R.J. Joyce, J.E. Janowiak, P.A. Arkin, P. Xie. "CMORPH: A method that produces global precipitation estimates from passive microwave and infrared data at high spatial and temporal resolution". J. Hydrometeorology, 5, 487-503, 2004.

[15] Food and Agriculture Organization of the United Nations. "Locust watch: Locust and Other Migratory Pests Group: Frequently Asked Questions (FAQs)". 